(principally in the cæcum); fluid contents taken from the cæcum of two of the lambs reacted to Fleitmann's test for arsenic. The curious features of the case are-the rapid fatality and the fact that only the half-breds were affected, not one of the pure-breds, which were mixed with and dipped with them, dying, or even showing the slightest departure from health. Whether this was due to any physiological or anatomical difference in their skin I cannot say.

Supposing a dipper dips two flocks of lambs for different owners, one of pure-breds and the other half-breds, using the same dip and process in each case, and suppose that a large majority of the halfbreds die, but none of the pure-bred flock: the owner of the former, naturally concluding that the dip and dipper were at fault, sues for damages; he would probably gain his case with ease, yet, as proved by the above, this might be a great injustice, as the deaths might entirely depend on some peculiar difference of the lambs.

\title{
A CASE OF INVAGINATION OF THE CACUM.
}

By E. M. JARvis, M.R.C.V.S., London.

PATIENT was a mare, the property of a cabman, who drove and looked after her himself. Age, twelve years.

History.-She had been in his possession eight years, and had worked in a cab all the time; she looked well fed, and certainly was in excellent condition for a cab horse.

During the first five years she had been a frequent subject of colic, and on the last occasion (three years ago) a groom who had been with a veterinary surgeon had applied mustard to the abdomen, and on the second day had taken away what he termed a "dung ball" of the size of a tennis ball. Since then I showed him a calculus which he said was similar.

On the I Ith June last she was seized with griping pains while in the cab, and the cabman had some difficulty to keep her from going down, and in getting to the Infirmary some distance off.

Symptoms.-I did not see her when first admitted, but I was informed that the same symptoms were then shown as are described below.

At 5.0 P.M. a gripe draught was given as follows:-

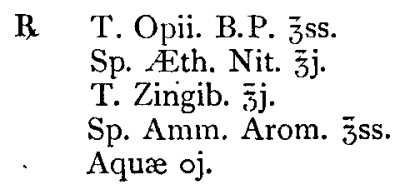

An hour and a half later I saw the mare for the first time. The owner was then preparing to take her away, she having a momentary fit of quietness, but noticing her to be very uneasy with her hind limbs, and pulse 6o, I advised him to give her an hour's rest, as he had a good way to go. During the next half hour, when not paddling with her hinds legs, she for some five or ten minutes kept the off hind leg flexed, with the fetlock knuckled over, and pointed with one of the fore feet, which position appeared to give her relief. 
7 P.M. Up till this time she had been kept tied up because the owner said if she lay down she could not get up, having always to be helped up when in health; but she was now let loose, and very soon lay down; once she half rolled on to her back, but this increased her pain, and she did not again attempt it while with us. She lay quiet for some time, except for occasionally raising her head, and craning her neck round to her flank, looking towards the front of the floor of the abdomen with a dolorous expression, and at the same time licking herself over the tubercle of the spine of the scapula; the side she lay on was the near side.

7.45 P.M. A draught as before was given.

8.20 P.M. Had her up, - but she had to be assisted as the owner said - and made a rectal exploration, which gave great pain; found about a handful of semi-fluid fæces saturated with uncoagulated blood. I now gave a cold injection of about two pints of water to which an ounce of liq. plumbi. subacet, had been added. Pressure was tried, but gave little pain except when exerted on the floor of the abdomen. When we let her head go she stood still for a few minutes, then walked into the corner of the box, stretched herself full out as if to urinate, and then raised her head, the nose "poked" in the air, and the neck fully extended; now and again she slowly lowered her head a few inches, and then jerked it up again, keeping the lips apart and the teeth in close apposition. The pulse about this time 65 , full but soft.

She soon lay down, now on the right side, but finding this uneasy got up, without assistance this time, and again lay down on the near side, looking round to her sides constantly, and evidently in considerable pain. She was given a dose of morphia subcutaneously, and for a while after she was quiet and showed no pain beyond an occasional up and down movement of the head, blinking of the eyelids, and pursing of the lips.

I0.30 P.M. She had one or two sharp attacks of pain, so was given another colic draught, and hot turpentine cloths were applied. At the same time, having in mind that a calculus might be causing part of the trouble, and in the hopes of affording relief to the intussusception which was suspected (although not of the cæcum), I gave her a dose of eserine hypodermically. This did not increase the pain, and the mare remained resting and comparatively easy until midnight, when she again got up and stretched as before, remaining so for quite five minutes, with her head in the corner. I noted at this time that a peculiar odour was exhaled from the skin-like that common to the alimentary tract. She soon after lay down again, looking round to her abdomen as before. The hot cloths were continuously applied, and I did not see her again until 3.I 5 A.M., when I made another rectal exploration, and took away a double handful of semi-fluid faces saturated with blood and possessing an extremely disagreeable odour ; another dose of morphia was then administered. The pulse was 72 and strong.

I $2 t /$, 6.30 A.M. She was unable to rise of herself this time, and it took four men to lift her up. A cold enema was again given with $\overline{3}$ j of liq. plumbi. subacet. in it. This was the last time she was able to keep up. Pulse 82.

During the day rugs wrung out of hot water were applied, stimulants 
being given to support her strength, and opiates to allay the pain. The animal was gradually sinking all the while, and died about I I.3O P.M.

Post-mortem Examination.-This showed the cæcum to be almost completely invaginated; only a few inches of it were to be seen, the rest of it having slipped into the first portion of the colon. About thirty or forty round worms (ascaris megalocephala) were present in the stomach and small intestines. When the first part of the large colon was laid open by a longitudinal incision, the invaginated cæcum, with its mucous surface outwards, was exposed. The whole of the invaginated part was of a livid colour from extreme venous congestion. ${ }^{1}$

As to how the invagination was brought about I can offer no theory, save that the mare may have overstrained herself in starting or stopping. The cab was a very heavy four-wheeler, and had four people inside and a good deal of luggage on top; the latter was just being set down when the mare was seized with the paroxysm of pain.

1 This remarkable specimen of invagination was brought to me from the knackers by Mr Jarvis, and I can vouch for the accuracy of the description which he has given.-J. M' 